\title{
Clinical Characteristics Of Patients With Asthma COPD Overlap (ACO) In Australian Primary Care
}

This article was published in the following Dove Press journal:

International Journal of Chronic Obstructive Pulmonary Disease

\author{
Gabriel Izbicki, (D) ${ }^{1,2}$ \\ Valerie Teo, ${ }^{1,3}$ Jenifer Liang, (D) ${ }^{4}$ \\ Grant M Russell, (D) ${ }^{5}$ \\ Anne E Holland, (D) ${ }^{6}$ \\ Nicholas A Zwar, ${ }^{7}$ \\ Billie Bonevski, (D) ${ }^{8}$ \\ Ajay Mahal, (D) ${ }^{9}$ \\ Paula Eustace, (DD ${ }^{10}$ Eldho Paul, ' \\ Kirsten Phillips, ' I \\ Sally Wilson, ${ }^{4,12}$ \\ Johnson George, ',4 \\ Michael J Abramson (iD) \\ 'School of Public Health \& Preventive \\ Medicine, Monash University, Melbourne, \\ Australia; ${ }^{2}$ Shaare Zedek Medical Center \\ and The Hebrew University Hadassah \\ Medical School, Jerusalem, Israel; ${ }^{3} \mathrm{National}$ \\ Healthcare Group Polyclinics, Singapore; \\ ${ }^{4}$ Centre For Medicine Use and Safety, \\ Faculty of Pharmacy and Pharmaceutical \\ Sciences, Monash University, Parkville, \\ Australia; ${ }^{5}$ Southern Academic Primary \\ Care Research Unit, Department of General \\ Practice, Monash University, Notting Hill, \\ Australia; ${ }^{6}$ Discipline of Physiotherapy, La \\ Trobe University and Alfred Health, \\ Melbourne, Australia; ${ }^{7}$ Faculty of Health \\ Sciences \& Medicine, Bond University, Gold \\ Coast, Australia; ${ }^{8}$ School of Medicine and \\ Public Health, University of Newcastle, \\ Callaghan, Australia; ${ }^{9}$ The Nossal Institute \\ For Global Health, University of Melbourne, \\ Melbourne, Australia; ${ }^{10}$ Eastern Melbourne \\ PHN (EMPHN), Box Hill, Australia; ' 'Lung \\ Foundation Australia (LFA), Milton, \\ Australia; ${ }^{12}$ Department of Infrastructure \\ Engineering, The University of Melbourne, \\ Melbourne, Australia
}

Correspondence: Michael J Abramson School of Public Health \& Preventive Medicine, 553 St Kilda Road, Melbourne, VIC 3004, Australia

Tel +6I 399030573

Fax +6I 399030556

Email michael.abramson@monash.edu
Purpose: Many older adults with a history of smoking and asthma develop clinical features of both asthma and COPD, an entity sometimes called asthma-COPD overlap (ACO). Patients with ACO may be at higher risk of poor health outcomes than those with asthma or COPD alone. However, understanding of ACO is limited in the primary care setting and more information is needed to better inform patient management. We aimed to compare the characteristics of patients with ACO or COPD in Australian general practices.

Patients and methods: Data were from the RADICALS (Review of Airway Dysfunction and Interdisciplinary Community-based care of Adult Long-term Smokers) trial, an intervention study of an interdisciplinary community-based model of care. Baseline demographic and clinical characteristics, pre- and post-bronchodilator spirometry, dyspnoea and St. George's Respiratory Questionnaire scores were compared between 60 ACO patients and 212 with COPD alone.

Results: Pre-bronchodilator Forced Expiratory Volume in 1 second (mean \pm SD $58.4 \pm 14.3$ vs $67.5 \pm 20.1 \%$ predicted) and Forced Vital Capacity (mean $82.1 \pm 16.9$ v $91.9 \pm 17.2 \%$ predicted) were significantly lower in the ACO group $(\mathrm{p}<0.001)$, but no difference was found in postbronchodilator spirometry. Demographic and clinical characteristics, dyspnoea, quality of life, comorbidities and treatment prescribed did not differ significantly between groups.

Conclusion: This is the first study describing the clinical characteristics of ACO patients in Australian general practices. Our finding of lower pre-bronchodilator lung function in the ACO group compared to those with COPD reinforces the importance of spirometry in primary care to inform management.

Trial registration: Australian New Zealand Clinical Trials Registry ACTRN12614001155684. Keywords: asthma, chronic obstructive pulmonary disease, primary care, spirometry

\section{Introduction}

Chronic obstructive pulmonary disease (COPD) ${ }^{1}$ and asthma ${ }^{2}$ are common chronic respiratory conditions that are associated with significant morbidity, mortality and high healthcare costs. ${ }^{3}$ COPD claimed 3 million lives globally in 2016, making it the fourth leading cause of death and by 2030 it is expected to be the third leading cause. ${ }^{4}$ Although there was a significant reduction in asthma deaths in Australia from 964 (standardised mortality rate 5.6/100,000/year) in 1989 following the publication of the Australian Asthma Management Plan ${ }^{5}$ to 447 (1.5/100,000/year) in 2008, ${ }^{6}$ there has been no further improvement either in Australia or internationally over the last decade. $^{7}$

Asthma and COPD have similar clinical manifestations; however, their underlying pathophysiological mechanisms and epidemiological features are distinct. ${ }^{8}$ 
This leads to difficulty in diagnosis when patients present with features of both conditions. It has been proposed that these patients have "asthma-COPD overlap (ACO)". ${ }^{9}$ ACO has been defined by the Global Initiative for Asthma (GINA) and Global initiative for Obstructive Lung Disease (GOLD) as persistent airflow limitation with several key characteristics typical of both asthma and COPD in the absence of an alternative diagnosis. Epidemiological studies have reported varying prevalence rates for ACO (ranging from $15 \%$ to $55 \%$ ) depending on age, sex and criteria used to define ACO in the sample. ${ }^{10-17}$ Definitions and diagnostic criteria are yet to be standardised for this relatively new condition. Better characterisation and understanding of ACO should be fundamental to improving the diagnosis, management and prognosis of patients presenting with features of mixed airways disease.

A global expert panel ${ }^{18}$ defined ACO as the presence of three major criteria: (1) significant smoking exposure, (2) chronic airflow limitation and (3) documented history of asthma, and at least one minor criterion out of (1) documented history of atopy or allergic rhinitis, (2) improvement of Forced Expiratory Volume in 1 second $\left(\mathrm{FEV}_{1}\right) \geq 12 \%$ and $\geq 200 \mathrm{~mL}$ or (3) elevated blood eosinophils. The National Asthma Council and Lung Foundation Australia have issued a joint information paper for health professionals that highlighted the age of onset, history, pattern of symptoms, lung function, longterm disease trajectory and chest X-ray findings of patients with ACO. ${ }^{19}$

However, there have been no published primary care studies in Australia comparing clinical characteristics or symptoms between patients with COPD alone and ACO. Better understanding of characteristics and differences between COPD and ACO may help clinicians identify patients with $\mathrm{ACO}$ and facilitate more appropriate management.

\section{Objective}

The primary objective of this study was to compare and contrast the demographic and clinical characteristics, dyspnoea, quality of life, comorbidities, treatment and lung function between primary care patients with COPD alone or ACO.

\section{Methods}

We used baseline data from the RADICALS (Review of Airway Dysfunction and Interdisciplinary Communitybased care of Adult Long-term Smokers) trial to compare the two groups. ${ }^{20}$ RADICALS was a cluster randomised controlled trial evaluating an interdisciplinary communitybased model of care in adult long-term smokers aimed at reducing the burden of smoking and COPD in Australian primary care. The study recruited patients aged 40 years or older, current or ex-smokers with a history of at least 10 pack-years of smoking, with or without an existing diagnosis of COPD, and who had at least two visits to the general practice in the previous year. The primary endpoint for the trial was changes in COPD-related quality of life as assessed by the St George's Respiratory Questionnaire (SGRQ). ${ }^{21}$

Detailed descriptions of baseline characteristics in the whole group have been published previously. ${ }^{22}$ COPD was confirmed by pre- and post-bronchodilator spirometry conducted in accordance with the American Thoracic Society/ European Respiratory Society guidelines. ${ }^{23}$ Following the Lung Foundation Australia's COPD-X guidelines, ${ }^{24}$ COPD was defined as $\mathrm{FEV}_{1}<80 \%$ predicted and $\mathrm{FEV}_{1} / \mathrm{FVC}<0.7$. ACO was defined for this analysis by acute bronchodilator reversibility, a key feature included in the definitions of ACO. ${ }^{18,25}$

Secondary endpoints included the COPD Assessment Test $(\mathrm{CAT})^{26}$ and the modified Medical Research Council (mMRC) dyspnoea scale. ${ }^{27}$ Demographic characteristics examined included age, sex, education, employment, marital status, living arrangements and household income. Clinical characteristics included comorbidities, the Charlson Comorbidity Index ${ }^{28}$ and medications, which were classified into those for respiratory and non-respiratory indications. Inhaled respiratory medications included short-acting betaagonists, short-acting antimuscarinics, long-acting beta-agonists (LABA), long-acting antimuscarinics (LAMA) and inhaled corticosteroids (ICS), alone or in combinations.

The RADICALS trial was registered with the Australian New Zealand Clinical Trials Registry (ACTRN12614001155684). The methods were performed in accordance with relevant guidelines and regulations including the Declaration of Helsinki and approved by Monash University's Human Research Ethics Committee. Written informed consent was provided by all participants. An appropriate research question/proposal that has received ethics approval would be considered by the investigators for sharing of individual de-identified participant data related to the analysis reported in this paper. The study protocol has already been published ${ }^{20}$ and the data codebook could be provided on request. The data would be made available on a secure Cloud server from the date of publication for 2 years. 


\section{Statistical Analysis}

Statistical analyses were performed using SPSS (ver 25, IBM, Armonk, NY) or Stata (ver 14, StataCorp, College Station, TX). Baseline characteristics were described using numbers (proportions), means \pm standard deviations (SD), or medians and interquartile ranges [IQR], depending on the type and distribution of data. Associations with ACO were assessed using $\chi^{2}$ tests. Differences between group means were assessed using Student's $t$-tests. As distributional assumptions were not satisfied, mMRC dyspnoea scores and numbers of conditions or medications were compared using Mann-Whitney $U$-tests. Adjustments were made to allow for clustering by practice (within practice correlations). A $P$-value $<0.05$ was considered to be statistically significant.

\section{Results}

Baseline interviews were conducted among 1050 patients from 41 practices. Case finding and spirometry identified 142 patients with a new diagnosis of COPD. Of 245 patients currently managed for COPD, 130 satisfied a spirometry-based definition. ${ }^{22}$ From this total of 272 participants with COPD, 60 (22\%) were identified to have spirometric features consistent with ACO.

Table 1 shows the demographic characteristics of patients with COPD alone ( $\mathrm{n}=212$ from 35 practices $)$ and those with ACO ( $\mathrm{n}=60$ from 25 practices). Age was similar across groups. Females and non-concession cardholders had greater prevalence of ACO than COPD, but none of the differences reached statistical significance. Most patients were still smoking daily. There was no significant difference in the duration of smoking, nor were there any differences in marital status, education, employment status, living arrangements or annual household income (data not shown).

The clinical characteristics of patients with ACO showed no significant differences compared to those of COPD alone (Table 2). However, the patients with ACO were slightly more likely to have a history of eczema $(11.7 \%)$ as compared to COPD alone $(4.4 \%)$. Neither were there any meaningful differences in the proportions of patients who had been prescribed any of the classes or combinations of inhaled respiratory medications nor numbers of non-respiratory medications.

Lung function, symptoms and quality of life in the two groups are compared in Table 3. Mean pre-bronchodilator $\mathrm{FEV}_{1}$ and FVC were both significantly lower in patients with ACO than in those with COPD alone. However, there were no significant differences in post-bronchodilator
Table I Demographic Characteristics Of Patients With COPD Alone Or Asthma COPD Overlap

\begin{tabular}{|c|c|c|c|c|}
\hline Characteristic & & $\begin{array}{l}\text { COPD } \\
\text { Alone } \\
(n=2 \mid 2)\end{array}$ & $\begin{array}{l}A C O \\
(n=60)\end{array}$ & P-value \\
\hline \multicolumn{5}{|l|}{ Age } \\
\hline & $\begin{array}{l}\text { Mean }( \pm S D) \\
\text { Years }\end{array}$ & $64.8( \pm 10.6)$ & $64.1( \pm 11.5)$ & 0.73 \\
\hline \multicolumn{5}{|l|}{ Gender } \\
\hline & $\begin{array}{l}\text { Male, } n(\%) \\
\text { Female }\end{array}$ & $\begin{array}{l}130(63.7) \\
74(36.3)\end{array}$ & $\begin{array}{l}32(53.3) \\
28(46.7)\end{array}$ & 0.15 \\
\hline \multicolumn{5}{|c|}{ Current smoking $(n=264)$} \\
\hline & $\begin{array}{l}\text { Daily, n (\%) } \\
\text { Occasional } \\
\text { Former smoker } \\
\text { Never smoked }\end{array}$ & $\begin{array}{l}\text { II } 8(57.8) \\
6(2.9) \\
79(38.7) \\
\text { I }(0.5)\end{array}$ & $\begin{array}{l}37(6 \mathrm{I} .7) \\
\mathrm{I}(\mathrm{I} .7) \\
21(35.0) \\
\mathrm{I}(\mathrm{I} .7)\end{array}$ & 0.61 \\
\hline \multicolumn{5}{|c|}{ History of smoking } \\
\hline & Years & $40.6( \pm 11.9)$ & $39.2( \pm 11.3)$ & 0.37 \\
\hline \multicolumn{5}{|c|}{ Marital status $(n=260)$} \\
\hline & $\begin{array}{l}\text { Married/De- } \\
\text { facto } \\
\text { Never married/ } \\
\text { Single } \\
\text { Separated/ } \\
\text { Divorced } \\
\text { Widowed }\end{array}$ & $\begin{array}{l}94(46.8) \\
40(19.9) \\
48(23.9) \\
19(9.5)\end{array}$ & $\begin{array}{l}25(42.4) \\
10(16.9) \\
19(32.2) \\
5(8.5)\end{array}$ & 0.46 \\
\hline \multicolumn{5}{|c|}{ Highest Education $(n=261)$} \\
\hline & $\begin{array}{l}\text { Primary } \\
\text { Education or } \\
\text { less } \\
\text { High School } \\
\text { Technical or } \\
\text { Further } \\
\text { education } \\
\text { University } \\
\text { Education }\end{array}$ & $\begin{array}{l}\text { I5 (7.4) } \\
95(47.0) \\
52(25.7) \\
40(19.8)\end{array}$ & $\begin{array}{l}3(5.1) \\
31(52.5) \\
18(30.5) \\
7(11.9)\end{array}$ & 0.49 \\
\hline \multicolumn{5}{|c|}{ Healthcare Concession Card $(n=260)$} \\
\hline & Yes & $147(73.1)$ & $35(59.3)$ & 0.08 \\
\hline
\end{tabular}

Abbreviations: COPD, chronic obstructive pulmonary disease; $A C O$, asthma COPD overlap; SD, standard deviation.

spirometry, symptoms or quality of life. Most of the patients reported only mild dyspnoea on exertion.

\section{Discussion}

This is the first study to characterise patients with ACO in Australian primary care. We found that $23 \%$ of the patients diagnosed with COPD through spirometry met criteria for 
Table 2 Clinical Characteristics And Treatment Of Patients With COPD Alone Or Asthma COPD Overlap

\begin{tabular}{|c|c|c|c|c|}
\hline & & COPD Alone $(n=203)$ & $\operatorname{ACO}(n=60)$ & P-Value \\
\hline Number of comorbid conditions & Median [IQR] & $4[2-6]$ & $3[2-6]$ & 0.62 \\
\hline Charlson comorbidity index & $(n=93)$ & $1[1-2]$ & I [I-2] & 0.72 \\
\hline History of eczema & $n(\%)(n=203)$ & $9(4.4 \%)$ & 7 (II.7\%) & 0.07 \\
\hline History of allergic rhinitis & & $5(2.5 \%)$ & $\mathrm{I}(\mathrm{l} .7 \%)$ & 0.71 \\
\hline History of chronic sinusitis & & $3(1.5 \%)$ & $3(5.0 \%)$ & 0.26 \\
\hline Short-acting beta-agonists & & $77(37.9 \%)$ & $20(33.3 \%)$ & 0.53 \\
\hline Short-acting antimuscarinics & & $6(3.0 \%)$ & $\mathrm{I}(\mathrm{I} .7 \%)$ & 0.59 \\
\hline Long-acting beta agonists (LABA) & & $78(38.4 \%)$ & $25(41.7 \%)$ & 0.70 \\
\hline Long-acting antimuscarinics (LAMA) & & $89(43.8 \%)$ & $23(38.3 \%)$ & 0.40 \\
\hline Inhaled corticosteroids (ICS) & & $80(39.4 \%)$ & $26(43.3 \%)$ & 0.64 \\
\hline$I C S+L A B A$ & & $72(35.5 \%)$ & $25(41.7 \%)$ & 0.45 \\
\hline LABA + LAMA & & $56(27.6 \%)$ & $16(26.7 \%)$ & 0.89 \\
\hline ICS + LABA + LAMA (Triple therapy) & & $50(24.6 \%)$ & $16(26.7 \%)$ & 0.75 \\
\hline Number of non-respiratory medications & Median [IQR] & $3[1-6]$ & $3.5[2-7]$ & 0.21 \\
\hline
\end{tabular}

Abbreviations: COPD, chronic obstructive pulmonary disease; ACO, asthma COPD overlap; IQR, interquartile range.

Table 3 Lung Function, Quality Of Life And Dyspnoea In Patients With COPD Alone Or Asthma COPD Overlap

\begin{tabular}{|c|c|c|c|}
\hline Mean (士SD) & COPD Alone $(n=204)$ & $A C O(n=60)$ & P-Value \\
\hline Pre-bronchodilator spirometry FEV (\%predicted) & $67.5( \pm 20.1)$ & $58.4( \pm \mid 4.3)$ & $<0.001$ \\
\hline FVC (\%predicted) & $91.9( \pm 17.2)$ & $82.1( \pm 16.9)$ & $<0.001$ \\
\hline $\mathrm{FEV}_{1} / \mathrm{FVC}$ & $0.56( \pm 0.12)$ & $0.55( \pm 0.10)$ & 0.36 \\
\hline Post-bronchodilator spirometry FEV (\%predicted) & $70.0( \pm 20.9)$ & $69.9( \pm 15.1)$ & 0.96 \\
\hline FVC (\%predicted) & $94.2( \pm 17.7)$ & $94.7( \pm 15.4)$ & 0.80 \\
\hline $\mathrm{FEV}_{1} / \mathrm{FVC}$ & $0.57( \pm 0.12)$ & $0.57( \pm 0.09)$ & 0.91 \\
\hline Quality of Life/Impact of COPD on life St George's Respiratory Questionnaire & $31.4( \pm 17.5)$ & $33.2( \pm 19.7)$ & 0.56 \\
\hline COPD Assessment Test & $13.0( \pm 7.5)$ & $13.5( \pm 8.3)$ & 0.68 \\
\hline \multicolumn{4}{|l|}{ Median [IQR] } \\
\hline Dyspnoea Modified MRC scale & I [0-2] & I [0-2] & 0.56 \\
\hline
\end{tabular}

Abbreviations: COPD, chronic obstructive pulmonary disease; ACO, asthma COPD overlap; SD, standard deviation; IQR, interquartile range; MRC, Medical Research Council.

ACO. Clearly, the prevalence of ACO is dependent on the definition used. In a population-based study from the Netherlands, ${ }^{29}$ Bonten et al concluded that differences in prevalence, patient characteristics and exacerbations reported in the literature were due to limited agreement on the definition of ACO, and therefore a consensus definition of ACO was urgently needed.

In our study we followed the definition for COPD recommended in the COPD- $\mathrm{X}$ guidelines and added the reversibility criteria as proposed by $\mathrm{Sin}$ et al. ${ }^{18}$ In the present analysis, no differences in demographic or clinical characteristics were observed between those with ACO and COPD. However, the pre-bronchodilator values of $\mathrm{FEV}_{1}$ and FVC (both absolute and \%predicted values) were significantly lower in the ACO group.

Some previous studies ${ }^{30,31}$ have reported that patients with ACO had significantly lower health-related quality of life as measured by the SGRQ. In the Latin-American Pulmonary Obstruction Investigation Project (PLATINO) study, $^{32}$ only 91 (1.8\%) out of 5044 subjects were classified as having $\mathrm{ACO}$ on the basis of post-bronchodilator $\mathrm{FEV}_{1} / \mathrm{FVC}<0.7$, acute bronchodilator reversibility and wheezing in the last year. In PLATINO, this overlap phenotype was associated with worse general health status, more hospitalizations and exacerbations compared with the reference COPD group. In a post hoc analysis of the Evaluation of COPD Longitudinally to Identify Predictive Surrogate End-points (ECLIPSE) study, ${ }^{33}$ the SGRQ total score was higher in patients with ACO defined by a history of asthma, as compared to COPD after adjusting for age, sex, baseline $\mathrm{FEV}_{1}$ and history of prior exacerbations. However, in our study, SGRQ score was related to sex and baseline $\mathrm{FEV}_{1}$, but not $\mathrm{ACO}$ (results not shown). 
Previous studies comparing lung function between COPD and ACO have reported inconsistent results. The ACO group had the lowest post-bronchodilator lung function values in some studies, ${ }^{30,32,34}$ while in others, better lung function has been reported. ${ }^{10,35}$ In a cross-sectional study of 9104 individuals from Korea, subjects with ACO showed significantly lower pre-bronchodilator lung function $\left(\mathrm{FEV}_{1}\right.$ \%predicted, $\mathrm{FVC}$ \%predicted and $\left.\mathrm{FEV}_{1} / \mathrm{FVC}\right)$ than either the asthma or the COPD group. ${ }^{36}$ Similar findings were also reported by PLATINO. ${ }^{32}$

There are also some comparative lung function data from clinical studies. Kauppi et al ${ }^{10}$ studied 1855 patients discharged with a diagnosis of asthma, COPD or both from a Finnish hospital over 11 years. Compared to COPD, the overlap group had higher pre-bronchodilator (FVC \%predicted) and post-bronchodilator $\left(\mathrm{FEV}_{1}\right.$ and $\mathrm{FVC} \%$ predicted) values but lower than the asthma group. Cosentino et $\mathrm{al}^{37} \mathrm{did}$ a retrospective analysis of the COPDGene study, a multicentre prospective observational study including 10,191 patients from 21 clinical centres. ACO patients had a higher $\mathrm{FEV}_{1} / \mathrm{FVC}$ ratio, $\mathrm{FEV}_{1} \%$ predicted and $\mathrm{FVC} \%$ predicted than COPD patients.

Many studies have reported that patients with ACO are younger than those with only COPD..$^{10,17,30-32}$ Sex differences have also been reported for ACO, with a higher prevalence among women $(4.0 \%)$ than in men $(2.2 \%),{ }^{38}$ while others found a higher prevalence among men. ${ }^{17,39}$

We found no statistically significant difference in the number of comorbidities nor the number of medications prescribed (respiratory and other) between the groups. While we did not find any significant difference in Charlson Comorbidity Index, these scores could only be calculated for a minority of patients because of missing data. In a subgroup analysis of the ECLIPSE study, ${ }^{33}$ it was found that the proportions of co-morbidities were higher in ACO patients (66\%), compared with COPD patients (43\%). However, both groups had similar prevalence of cardiovascular diseases. There were no significant differences between ACO and COPD in comorbidities other than rhinitis in an analysis of the British Optimum Patient Care Research Database. ${ }^{17}$

Other studies reported that significantly more inhaled therapy, especially ICS in combination with LABA, were used by ACO patients than COPD..$^{40,41}$ We found that $39 \%$ of the COPD patients received ICS, but $57 \%$ of the ACO patients did not receive ICS. We did not expect such a high proportion of ICS users among those with COPD, neither would we expect such a high proportion of patients with
ACO not receiving ICS. We had no influence on the treatments given by the GPs, but these unexpected proportions highlight the need for more studies on ACO and specifically on the most appropriate treatment.

A strength of our study is that it was a real-life assessment recruiting heavy smokers newly diagnosed with COPD and those already being treated for COPD in multiple primary care clinics with a large number of GPs. Such clustering minimised the risk of contamination associated with the same practice staff treating all the patients and appropriate statistical adjustment for clustering was performed.

However, there were also some limitations in this study. Firstly, we had no group of patients with asthma alone, unlike other studies. ${ }^{17,32,35} \mathrm{An}$ asthma group would have allowed us to compare ACO not only with COPD but also to patients with asthma alone. We did not have data on bronchial hyper-reactivity, eosinophil counts or atopy. These were however clearly beyond the scope of the general RADICALS trial. ${ }^{20}$

An important limitation was the definition of ACO. We used the reversibility criteria proposed by Sin et al. ${ }^{18} \mathrm{An}$ $\mathrm{FEV}_{1}$ or $\mathrm{FVC}$ improvement of $\geq 200 \mathrm{~mL}$ or $12 \%$ from baseline values is the criterion recommended by the American Thoracic Society (ATS) for significant bronchodilator response. ${ }^{42}$ However, we agree that this cut-off is not ideal to separate asthma from COPD. Indeed the Spanish Society of Pulmonology and Thoracic Surgery (SEPAR) has recommended in order to improve the diagnostic performance, the use of $15 \%$ and $400 \mathrm{~mL}$ as the cutoff for patients with only one spirometric measurement or the traditional $12 \%$ and $200 \mathrm{~mL}$ cut-off for those with multiple measurements. ${ }^{43}$ The majority of our patients had multiple measurements and therefore our definition was also in accordance with SEPAR. However, we agree that none of these cut-off values are perfect for clearly separating asthma and COPD.

Another limitation was that due to the relatively small number of ACO patients and non-smokers, this posthoc analysis was underpowered to detect some differences in secondary outcomes between the groups. We also accept that general practices that chose to participate in the trial might not be representative of all practices in Australia, so the findings should be generalised with caution. Finally, we had some missing data especially in comorbidities and medications.

Nonetheless, our findings have significant implications for the management of long-term smokers in primary care. 
The benefits may include further justification of spirometry, which would open the door to better targeted treatment, because of differences in the optimal treatment of the two conditions. The findings could also increase the proportion getting care in accordance with local guidelines such as the COPD-X. ${ }^{24}$ With the advent of precision medicine, there is now greater focus on "treatable traits" rather than diagnostic labels. ${ }^{44}$ The pulmonary treatable traits relevant to airways disease in these patients include airflow limitation, eosinophilic airway inflammation and chronic bronchitis, among others which can co-exist.

\section{Conclusion}

In this study, which was the first to characterize ACO in a large group of smokers/former smokers and those managed as having COPD at general practices in Australia, we found that only the pre-bronchodilator lung function was lower in the ACO subpopulation. The ACO and COPD groups otherwise had similar demographic and clinical characteristics, dyspnoea and quality of life. The present study and the available literature highlight the importance of performing spirometry for accurate diagnosis in primary care. Larger-scale primary care-based studies focusing on ACO and treatable traits could bring further insights and help clinicians to better characterize, understand and treat this condition.

\section{Acknowledgments}

This trial was funded by the National Health and Medical Research Council (NHMRC) through the NHMRC Partnerships for Better Health - Partnership Projects initiative (APP1076255). Cash and in-kind contributions were received from our partner organisations, Lung Foundation Australia (LFA), Boehringer Ingelheim, and Eastern Melbourne PHN (EMPHN). The LFA and EMPHN were involved in project design and conduct and contributed to data analysis and writing of manuscripts. Boehringer Ingelheim was involved in project discussions, planning and progress review, but had no involvement in the design of the intervention program, and did not contribute to decisions about data analysis and the dissemination of findings. Billie Bonevski was supported by an NHMRC Career Development Fellowship (GNT1063206) and a Faculty of Health and Medicine, University of Newcastle, Gladys M. Brawn Career Development Fellowship. Jenifer Liang received the Cyril Tonkin Scholarship 2014, administered by the Victorian College of Pharmacy Foundation Board, Monash University. We thank Denise van den Bosch (contributions to project management and data extraction), Narelle Cox and all research assistants, students, clinics and participants. Interim findings from this paper were presented at the Thoracic Society of Australia \& New Zealand Annual Scientific Meeting on the Gold Coast in 2019 as an oral presentation. The presentation abstract was published in TSANZSRS Conference Abstracts in Respirology 2019 Mar;24 Suppl 1:4-206. doi: 10.1111/resp.13491.

\section{Author Contributions}

The RADICALS trial was designed, and funding obtained by JG, GMR, AEH, NAZ, BB, AM, PE, KP and MJA. Data were collected and managed under the supervision of JG, JL and SW. This analysis of baseline data for ACO was planned by MJA, GI, VT and JG. Statistical analysis was conducted by MJA, VT and EP. The findings were interpreted, and the first draft written by GI, VT and MJA. All authors contributed to drafting and revising the manuscript and approved the final version for publication. MJA and JG act as guarantors, and all authors agree to be accountable for those aspects of the work within their areas of expertise.

\section{Disclosure}

Michael J Abramson holds an investigator-initiated grant from Pfizer for unrelated research. He has also conducted an unrelated consultancy for Sanofi and reports grants from Boehringer-Ingelheim, during the conduct of the study. Johnson George has held investigator-initiated grants from Pfizer for unrelated research and has received cash and inkind contributions from Boehringer Ingelheim (BI) Pty Ltd for an unrelated project. He has received an honorarium from GSK for consultancy. He also received non-financial support from the Lung Foundation Australia, grants from the National Health and Medical Research Council, non-financial support from the Inner East Melbourne Primary Health Network, during the conduct of the study and grants and personal fees from GSK and grants from Pfizer, outside the submitted work. Professor Anne E Holland reports grants from the National Health and Medical Research Council, grants from Boehringer Ingelheim, non-financial support from Lung Foundation Australia, and non-financial support from Eastern Melbourne PHN, during the conduct of the study. Ms Jenifer Liang reports grants and non-financial support from Boehringer Ingelheim, non-financial support from the Lung Foundation Australia, non-financial support from Eastern Melbourne PHN, and grants from National Health and Medical Research Council 
(Australia), during the conduct of the study. The authors report no other conflicts of interest in this work.

\section{References}

1. Global Initiative for Chronic Obstructive Lung Disease. Global strategy for the diagnosis, management, and prevention of COPD; 2017. Available from: http://goldcopd.org/gold-2017-global-strategy-diagno sis-management-prevention-copd/. Accessed July 27, 2018.

2. Global Initiative for Asthma. GINA report, global strategy for asthma management and prevention; 2018. Available from: https:// ginasthma.org/2018-gina-report-global-strategy-for-asthma-manage ment-and-prevention/. Accessed July 27, 2018.

3. Department of Health. Chronic respiratory conditions - including asthma and chronic obstructive pulmonary disease (COPD); 2018 Available from: http://www.health.gov.au/internet/main/publishing. nsf/Content/chronic-respiratory. Accessed July 27, 2018.

4. World Health Organization (WHO). The top 10 causes of death; 2018. Available from: http://www.who.int/en/news-room/fact-sheets/ detail/the-top-10-causes-of-death. Accessed July 27, 2018.

5. Woolcock A, Rubinfeld AR, Seale JP, et al. Thoracic society of Australia and New Zealand. Asthma management plan, 1989. Med J Aust. 1989;151(11-12):650-653. doi:10.5694/j.1326-5377.1989.tb139640.x

6. Comino E. Asthma mortality in Australia 1960-2008; 2010. Available from: https://assets.nationalasthma.org.au/resources/26-19602008update.pdf. Accessed October 22, 2018.

7. Ebmeier S, Thayabaran D, Braithwaite I, Benamara C, Weatherall M, Beasley R. Trends in international asthma mortality: analysis of data from the WHO Mortality Database from 46 countries (19932012). Lancet. 2017;390(10098):935-945. doi:10.1016/S01406736(17)31448-4

8. Marsh SE, Travers J, Weatherall M, et al. Proportional classifications of COPD phenotypes. Thorax. 2008;63(9):761-767. doi:10.1136/ thx.2007.089193

9. Global Initiative for Chronic Obstructive Lung Disease. Asthma, COPD and asthma-COPD overlap syndrome; 2015. Available from: http://goldcopd.org/asthma-copd-asthma-copd-overlap-syndrome/. Accessed July 27, 2018.

10. Kauppi P, Kupiainen H, Lindqvist A, et al. Overlap syndrome of asthma and COPD predicts low quality of life. J Asthma. 2011;48 (3):279-285. doi: $10.3109 / 02770903.2011 .555576$

11. Barrecheguren M, Esquinas C, Miravitlles M. The asthma-chronic obstructive pulmonary disease overlap syndrome (ACOS): opportunities and challenges. Curr Opin Pulm Med. 2015;21(1):74-79. doi:10.1097/MCP.0000000000000118

12. Louie S, Zeki AA, Schivo M, et al. The asthma-chronic obstructive pulmonary disease overlap syndrome: pharmacotherapeutic considerations. Expert Rev Clin Pharmacol. 2013;6(2):197-219. doi:10.1586/ ecp. 13.2

13. Zeki AA, Schivo M, Chan A, Albertson TE, Louie S. The asthmaCOPD overlap syndrome: a common clinical problem in the elderly. J Allergy (Cairo). 2011;2011:861926.

14. Andersen H, Lampela P, Nevanlinna A, Saynajakangas O, Keistinen T. High hospital burden in overlap syndrome of asthma and COPD. Clin Respir J. 2013;7(4):342-346. doi:10.1111/ crj.2013.7.issue-4

15. McDonald VM, Simpson JL, Higgins I, Gibson PG. Multidimensional assessment of older people with asthma and COPD: clinical management and health status. Age Ageing. 2011;40(1):42-49. doi:10.1093/ ageing/afq134

16. Soriano JB, Davis KJ, Coleman B, Visick G, Mannino D, Pride NB. The proportional Venn diagram of obstructive lung disease: two approximations from the United States and the United Kingdom. Chest. 2003;124(2):474-481. doi:10.1378/chest.124.2.474
17. Krishnan JA, Nibber A, Chisholm A, et al. Prevalence and characteristics of asthma-COPD overlap in routine primary care practices. Ann Am Thorac Soc. 2019;16:1143-1150. doi:10.1513/AnnalsATS.201809$607 \mathrm{OC}$

18. Sin DD, Miravitlles M, Mannino DM, et al. What is asthma-COPD overlap syndrome? Towards a consensus definition from a round table discussion. Eur Respir J. 2016;48(3):664-673. doi:10.1183/ 13993003.00436-2016

19. National Asthma Council Australia, Lung Foundation Australia; 2017. Asthma-COPD overlap. National Asthma Council Australia. https://lungfoundation.com.au/wp-content/uploads/2017/12/ACOPD-overlap-info-paper-20171204-final.pdf. Accessed November 01, 2017.

20. Liang JAM, Zwar N, Russell G, et al. An interdisciplinary model of care (RADICALSC) for early detection and management of chronic obstructive pulmonary disease (COPD) in Australian primary care: study protocol for a cluster randomised controlled trial. BMJ Open. 2017;7(9). doi:10.1136/bmjopen-2017-016985

21. Jones PW. Measurement of Health-Related Quality of Life in Asthma and Chronic Airways Disease. Dordrecht; Boston: Kluwer Academic Publishers; 1993:301-320.

22. Liang JAM, Zwar N, Russell G, et al. Diagnosing chronic obstructive pulmonary disease (COPD) and smoking cessation support provided in general practices: gaps between evidence and current practice. Med J Aust. 2018;208(1):29-34. doi:10.5694/mja17.00664

23. Miller MR, Hankinson J, Brusasco V, et al. Standardisation of spirometry. Eur Respir J. 2005;26(2):319-338. doi:10.1183/09031936. 05.00034805

24. Abramson MJ, Frith P, Halcomb E, et al. COPD-X: concise guide for primary care. Brisbane: Lung Foundation Australia; 2017: https:// lungfoundation.com.au/wp-content/uploads/2014/11/LFA-COPD-Xdoc_FINAL-190917.pdf. Accessed July 30, 2018.

25. Soler-Cataluna JJ, Cosio B, Izquierdo JL, et al. Consensus document on the overlap phenotype COPD-asthma in COPD. Arch Bronconeumol. 2012;48(9):331-337. doi:10.1016/j.arbr.2012.06.017

26. Jones PW, Harding G, Berry P, Wiklund I, Chen WH, Kline Leidy $\mathrm{N}$. Development and first validation of the COPD Assessment Test. Eur Respir J. 2009;34(3):648-654. doi:10.1183/090319 36.00102509

27. Bestall J, Paul E, Garrod R, Garnham R, Jones P, Wedzicha J. Usefulness of the Medical Research Council (MRC) dyspnoea scale as a measure of disability in patients with chronic obstructive pulmonary disease. Thorax. 1999;54(7):581-586. doi:10.1136/ thx.54.7.581

28. Charlson ME, Pompei P, Ales KL, MacKenzie CR. A new method of classifying prognostic comorbidity in longitudinal studies: development and validation. $J$ Chronic Dis. 1987;40(5):373-383. doi:10.1016/0021-9681(87)90171-8

29. Bonten TN, Kasteleyn MJ, de Mutsert R, et al. Defining asthmaCOPD overlap syndrome: a population-based study. Eur Respir J. 2017;49(5):1602008. doi:10.1183/13993003.02008-2016

30. Miravitlles M, Soriano JB, Ancochea J, et al. Characterisation of the overlap COPD-asthma phenotype. Focus on physical activity and health status. Respir Med. 2013;107(7):1053-1060. doi:10.1016/j. rmed.2013.03.007

31. Hardin M, Silverman E, Barr RG, et al. The clinical features of the overlap between COPD and asthma. Respir Res. 2011;12(1):127. doi:10.1186/1465-9921-12-127

32. Menezes AMB, Montes de Oca M, Perez-Padilla R, et al. Increased risk of exacerbation and hospitalization in subjects with an overlap phenotype: COPD-asthma. Chest. 2014;145(2):297-304. doi:10.13 78/chest.13-0622

33. Wurst KE, Rheault TR, Edwards L, Tal-Singer R, Agusti A, Vestbo J. A comparison of COPD patients with and without ACOS in the ECLIPSE study. Eur Respir J. 2016;47(5):1559-1562. doi:10.1183/ 13993003.02045-2015 
34. A ZZ A, Albanyan O, Dairi M, FitzGerald JM. Asthma and COPD Overlap Syndrome (ACOS): a systematic review and meta analysis. PLoS ONE. 2015;10(9):e0136065.

35. Fabbri LM, Romagnoli M, Corbetta L, et al. Differences in airway inflammation in patients with fixed airflow obstruction due to asthma or chronic obstructive pulmonary disease. Am J Respir Crit Care Med. 2003;167(3):418-424. doi:10.1164/rccm.200203-183OC

36. Chung JW, Kong KA, Lee JH, Lee SJ, Ryu YJ, Chang JH. Characteristics and self-rated health of overlap syndrome. Int J Chron Obstruct Pulmon Dis. 2014;9:795-804. doi:10.2147/COPD.S61093

37. Cosentino J, Zhao H, Hardin M, et al. Analysis of asthma-chronic obstructive pulmonary disease overlap syndrome defined on the basis of bronchodilator response and degree of emphysema. Ann Am Thorac Soc. 2016;13(9):1483-1489. doi:10.1513/AnnalsATS.201511-761OC

38. Wheaton AG, Pleasants RA, Croft JB, et al. Gender and asthmachronic obstructive pulmonary disease overlap syndrome. J Asthma. 2016;53(7):720-731. doi:10.3109/02770903.2016.1154072

39. Sharma R, Jha O, Prajapat D, Talwar D. Prevalence and profile of asthma COPD overlap (ACO) in previously diagnosed COPD patients - an observational study from north India. Respirology. 2017;22(S3):244-245.
40. Izquierdo-Alonso JL, Rodriguez-Gonzalezmoro JM, de Lucas-ramos $\mathrm{P}$, et al. Prevalence and characteristics of three clinical phenotypes of chronic obstructive pulmonary disease (COPD). Respir Med. 2013;107(5):724-731. doi:10.1016/j.rmed.2013.01.001

41. Rhee CK, Yoon HK, Yoo KH, et al. Medical utilization and cost in patients with overlap syndrome of chronic obstructive pulmonary disease and asthma. COPD. 2014;11(2):163-170. doi:10.3109/ 15412555.2013.831061

42. Pellegrino R, Viegi G, Brusasco V, et al. Interpretative strategies for lung function tests. Eur Respir J. 2005;26(5):948-968. doi:10.1183/ 09031936.05.00035205

43. Plaza V, Alvarez F, Calle M, et al. Consensus on the asthma-COPD overlap syndrome (ACOS) between the Spanish COPD guidelines (GesEPOC) and the Spanish Guidelines on the Management of Asthma (GEMA). Arch Bronconeumol. 2017;53(8):443-449. doi:10.1016/j.arbres.2017.04.002

44. Agusti A, Bel E, Thomas M, et al. Treatable traits: toward precision medicine of chronic airway diseases. Eur Respir J. 2016;47(2):410419. doi:10.1183/13993003.01359-2015

\section{Publish your work in this journal}

The International Journal of COPD is an international, peer-reviewed journal of therapeutics and pharmacology focusing on concise rapid reporting of clinical studies and reviews in COPD. Special focus is given to the pathophysiological processes underlying the disease, intervention programs, patient focused education, and self management protocols. This journal is indexed on PubMed Central, MedLine and CAS. The manuscript management system is completely online and includes a very quick and fair peer-review system, which is all easy to use. Visit http://www.dovepress.com/testimonials.php to read real quotes from published authors. 